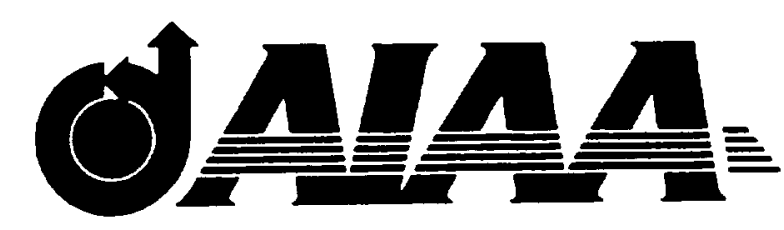

NASA-TM-112019

\title{
AIAA 95-1858
}

\section{Optimization of An Advanced Design Three-Element Airfoil at High Reynolds Numbers}

J. C. Lin

NASA Langley Research Center Hampton, VA

C. J. Dominik McDonnell Douglas Aerospace Long Beach, CA

\section{AIAA 13th Applied Aerodynamics Conference June 19 - 22, 1995 / San Diego, CA}




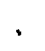




\title{
OPTIMIZATION OF AN ADVANCED DESIGN THREE-ELEMENT AIRFOIL AT HIGH REYNOLDS NUMBERS
}

\author{
John C. Lin* \\ Fluid Mechanics and Acoustics Division \\ NASA Langley Research Center \\ Mail Stop 170 \\ Hampton, VA 23681-0001 \\ and \\ Chet J. Dominik $\dagger$ \\ Advanced Transport Aircraft Development \\ McDonnell Douglas Aerospace \\ 1510 Hughes Way, MC 71-35 \\ Long Beach, CA 90810-1870
}

\begin{abstract}
New high-lift components have been designed for a three-element advanced high-lift research airfoil using a state-of-the-art computational method. The new components were designed with the aim to provide high maximum-lift values while maintaining attached flow on the single-segment flap at approach conditions. This three-element airfoil has been tested in the NASA Langley Low-Turbulence Pressure Tunnel at chord Reynolds number up to 16 million. The performance of the NASA research airfoil is compared to a reference advanced high-lift research airfoil. Effects of Reynolds number on slat and flap rigging have been studied experimentally. The performance trend of this new high-lift design is comparable to that predicted by the computational method over much of the angle of attack range. Nevertheless, the method did not accurately predict the airfoil performance or the configuration-based trends near maximum lift.

* Senior Research Engineer, Flow Modeling and Control Branch, Member AIAA.

$\dagger$ Engineer/Scientist Specialist, Subsonic Aerodynamics Technology Group, Member AIAA.

Copyright $\Theta 1995$ by the American Institute of Aeronautics and Astronautics, Inc. No copyright is asserted in the United States under Title 17, U.S. Code. The U.S. Government has a royaltyfree license to exercise all rights under the copyright claimed herein for government purposes. All other rights are reserved by the copyright owner.
\end{abstract}

\section{Nomenclature}

c cruise or stowed airfoil chord

$\mathrm{C}_{\mathrm{d}}$ drag coefficient

$\mathrm{C}_{\ell} \quad$ lift coefficient

$\mathrm{C}_{\mathrm{p}}$ pressure coefficient

EET Energy Efficient Transport

LTPT Low-Turbulence Pressure Tunnel

M Mach number

$\mathrm{Re}_{\mathrm{c}}$ Reynolds number based on cruise chord $\mathrm{c}$

WUSS wing-under-slat surface

$x \quad$ coordinate along the chord direction

$\alpha \quad$ angle of attack

Subscripts

min minimum value

te trailing-edge value

$\infty \quad$ freestream value

\section{Introduction}

A major objective of aircraft manufacturers is to reduce aircraft cost. One possible way to reach that objective is to build simpler and cheaper high-lift systems (single-segment flaps). This presents a challenge to the high-lift aerodynamicist: to design a single-segment flap that maintains high levels of maximum lift while minimizing flow separation. Furthermore, by reducing the number of elements in the high-lift system and maintaining attached flow on the flap, aircraft noise will be reduced.

In the past several years, a significant amount of data has been published on high Reynolds number component optimization ${ }^{1-4}$. New high-lift components were fabricated for an existing NASA 
four-element high-lift research airfoil designed in the mid-70's $\mathrm{s}^{5}$. This model is being used to expand the existing database of Reynolds number and Mach number effects on high-lift airfoils. In addition, this model provides a representative modern high-lift system for subsequent turbulence model investigations. A new slat, wing-under-slat surface (WUSS), spoiler, flap shelf and single-segment flap were designed by the Advanced Transport Aircraft Development segment of McDonnell Douglas Aerospace (under contract to NASA Langley), using a state-of-the-art computational method ${ }^{6}$. These model parts were designed with the goal of maintaining high levels of maximum lift, while minimizing flow separation.

This paper describes the design of the new highlift components and the results of high Reynolds number wind-tunnei tests to explore the optimization of the component rigging (gap and overhang) of the slat and flap. All of the experimental results shown in this report were obtained in the NASA Langley Low-Turbulence Pressure Tunnel ${ }^{7}$ (LTPT). The objective of these initial experiments was to calibrate the design tool, and expand the existing database $^{1-4}$ of high-lift aerodynamic data for future CFD code calibration.

\section{LTPT Test Facility}

The Langley Low-Turbulence Pressure Tunnel is a single-retum, closed-loop wind tunnel (Figure 1) that can be operated at pressures up to 10 atmospheres thus providing very high Reynolds number capability ${ }^{7}$. The test section is 3 feet wide by 7.5 feet high by 7.5 feet long. Most of the testing was conducted at a freestream Mach number, $M_{\infty}$, of 0.20 and Reynolds numbers based on cruise (stowed) chord, $\operatorname{Re}_{\mathrm{c}}$, of $4.2,9$, and $16 \times 10^{6}$. The $4.2 \times 10^{6}$ Reynolds number case represents a typical windtunnel condition for full-span, three-dimensional (3D) tests, while the 9 and $16 \times 10^{6}$ Reynolds number cases represent the flight conditions for an outboard and an inboard wing station, respectively, of a representative narrow-body transport. To promote two-dimensional flow, a passive sidewall boundarylayer control (BLC) system was used ${ }^{8}$. The BLC system utilized the differential pressure between the test section and the atmosphere to provide suction (venting) of the sidewall boundary layer through porous endplates. Good two-dimensional flow quality was observed (as indicated by the spanwise pressure distributions on the model) for the range of Reynolds numbers and flow conditions tested in this study.
The LTPT was designed with a large contraction ratio (17 to 1) and 9 antiturbulence screens to produce extremely low-turbulence levels ${ }^{9}$ (less than $0.5 \%$ for most cases). Due to the ability of the LTPT to provide flight Reynolds numbers for representative narrow-body transports, the model was tested transition free (not fixed). However, further work is needed to determine the proper viscous-simulation technique to best represent full-scale 3D flow conditions for a range of flight Reynolds number conditions.

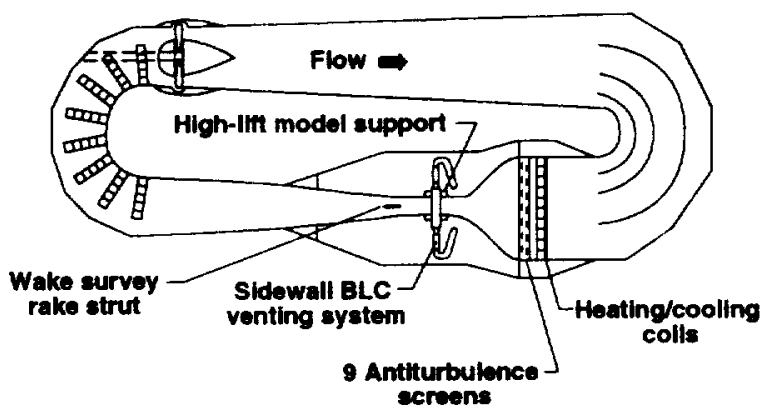

Figure 1. Schematic of the Low-Turbulence Pressure Tunnel (LTPT).

\section{Model Description}

The NASA high-lift model is derived from an existing $12 \%$ thick supercritical airfoil of the Energy Efficient Transport (EET) class $^{5}$ (shown in Figure 2). The NASA EET cruise airfoil is thicker than the reference cruise airfoil ${ }^{2}$, and has more (aft) camber, as shown in Figures 2 through 4 . The NASA model spanned the width of the test section and had a clean (stowed) chord of 21.654 inches. A diagram of the three-element airfoil tested is shown in Figure 5. The slat chord is $14.48 \%$, the main-element chord is $83.06 \%$, and the flap chord is $30 \%$ of the stowed airfoil chord. Pressure orifices were located along the centerline of the model (156 taps for the threeelement configuration) and along the span at chordwise stations of $5 \%, 74 \%, 87.4 \%$, and the trailing edge (all values are normalized with respect to the stowed chord). Surface pressures were measured via eight Electronic Sensing Pressure (ESP) modules calibrated appropriately for the range of test conditions and measurements. Accuracy of the ESP modules was $\pm 0.1 \%$ of full-scale value. Integration of pressure measurements yielded the forces presented in this publication. The drag data presented in this publication were computed by integration of the static and total pressures obtained from a 5-hole-probe wake-survey system reported in Reference 10 . 


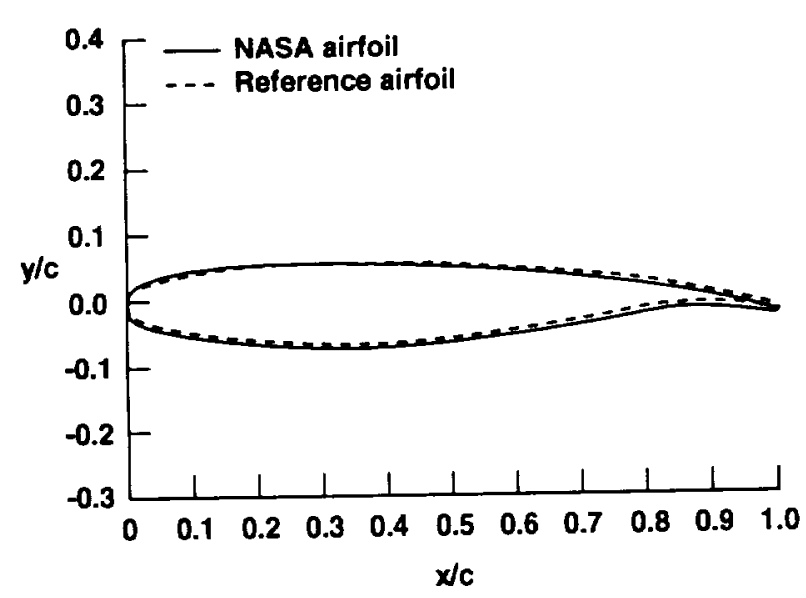

Figure 2. Comparison of the cruise geometry between the NASA and reference airfoils.

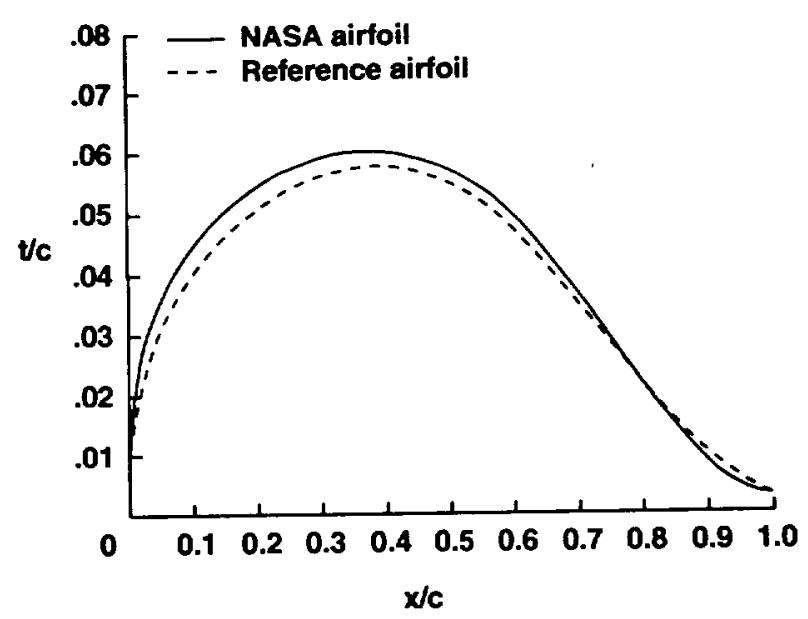

Figure 3. Comparison of the thickness distribution between the NASA and reference airfoils.

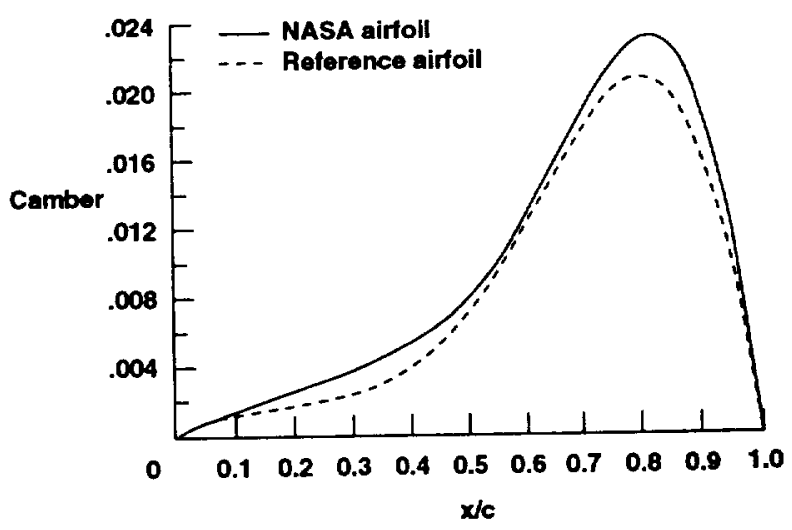

Figure 4. Comparison of the camber distribution between the NASA and reference airfoils.

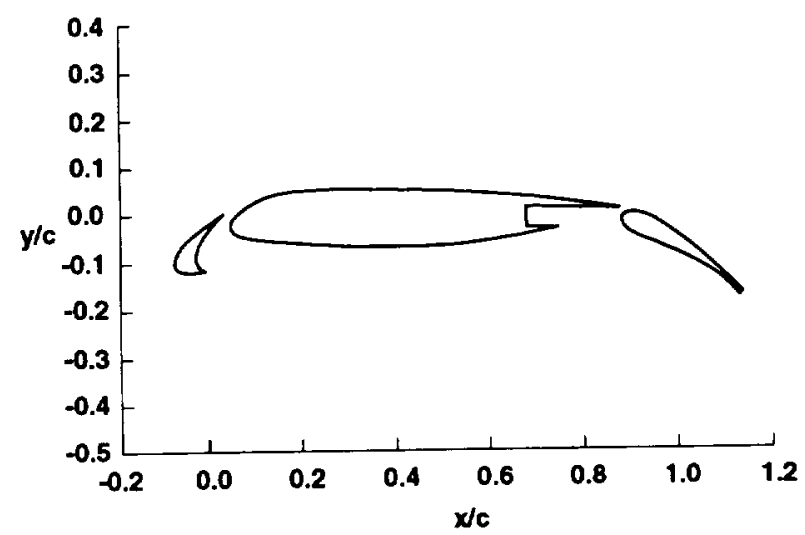

Figure 5. Geometry of the NASA high-lift research airfoil.

Four rows of streamlined brackets were needed to support the high-lift configuration (Figure 6) due to the very high loads developed at the high test pressures. The nomenclature defining the key geometric parameters of high-lift systems is shown in Figure 7. All gap and overhang values in this paper are expressed in terms of percent of cruise chord (all high-lift components stowed), \%c.

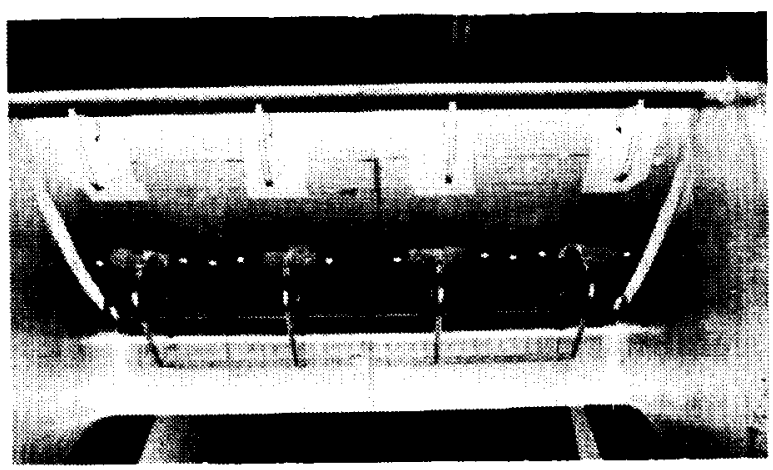

Figure 6. Photograph of the lower surface of the NASA advanced high-lift research airfoil in LTPT (view looking downstream).

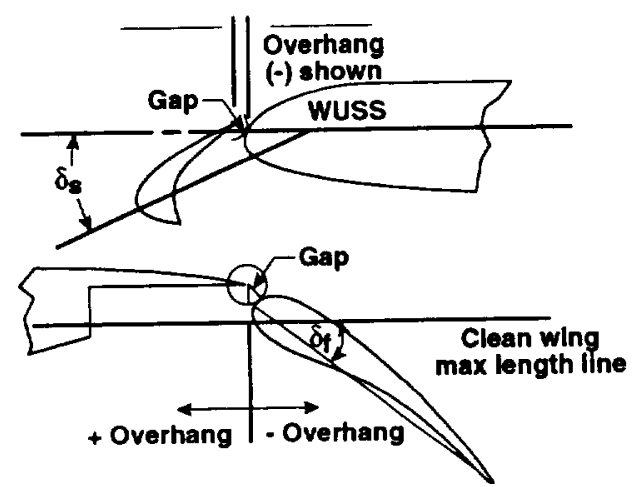

Figure 7. Nomenclature for multi-element airfoils. 


\section{High-Lift System Design}

The new high-lift system was designed with the objective of achieving high levels of performance while maintaining attached flow on the singlesegment flap at flight Reynolds numbers. The highlift system was designed to achieve maximum-lift levels similar to the reference single-segment flap". Before the high-lift system design was begun, it was instructive to compare the performance of the two cruise airfoils (Figures 2 through 4). As stated previously, the NASA cruise airfoil does have increased aft camber that will allow it to generate more lift than the reference airfoil ${ }^{2}$. The structuredgrid, incompressible Navier-Stokes code, INS2D ${ }^{6}$, with the Baldwin-Barth turbulence model was used for the computational analysis of the NASA and reference airfoils. The INS2D predictions indicated that the NASA cruise airfoil would produce more lift than the reference airfoil at all angles of attack (shown in Figure 8).

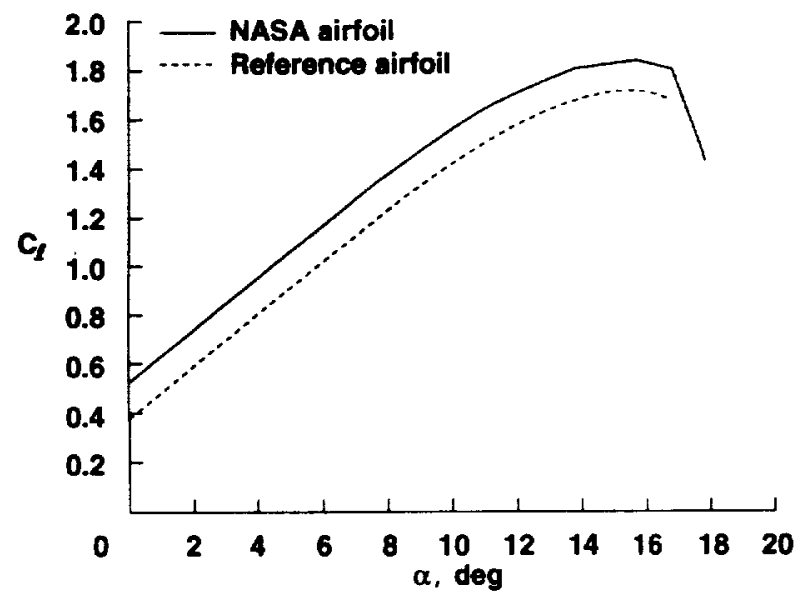

Figure 8. INS2D predicted lift curve comparison between the NASA and reference cruise airfoils $\left(\operatorname{Re}_{c}=9 \times 10^{6}\right)$.

For the new high-lift components, no variable (or mission adaptive) designs were considered. The new flap was similar in shape to the flap of Reference 4 . The flap was designed to have minimal flow separation at a $30^{\circ}$ flap setting with no overlap between the flap leading edge and the spoiler trailing edge. The INS2D predictions for the NASA threeelement configuration indicated it would have improved performance compared to the reference three-element airfoil ${ }^{4}$ (Figure 9). This predicted improvement is largely attributable to the increased (aft) camber of the NASA airfoil.

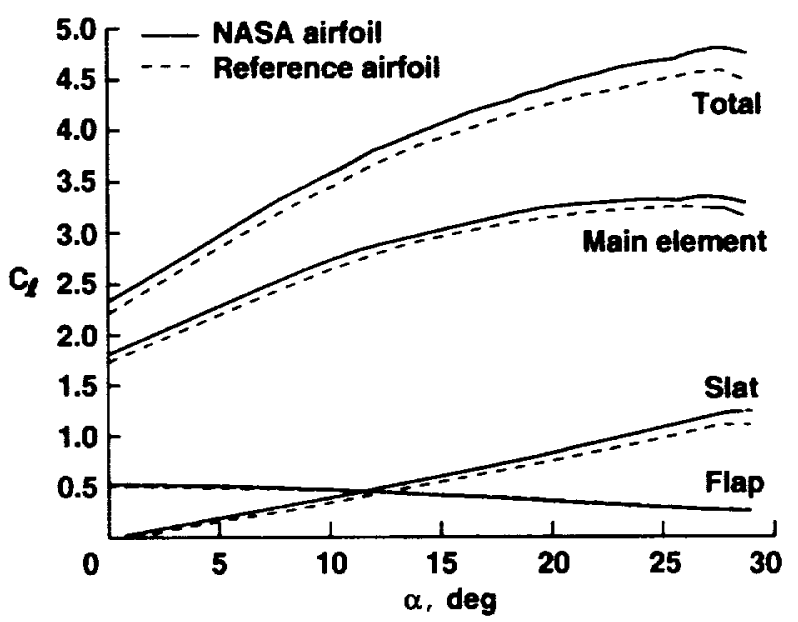

Figure 9. INS2D predicted lift curve comparison between the NASA and reference highlift airfoils $\left(\operatorname{Re}_{\mathrm{c}}=9 \times 10^{6}\right)$.

\section{Experimental_Results}

The following discussion reviews highlights of the subject test results obtained in the NASA Langley LTPT. The NASA cruise and high-lift airfoils were tested and the experimental results were compared to INS2D predictions, as well as to the results of their respective reference airfoil counterpart. Effects of varying the slat and flap gaps and overhangs of the NASA airfoil were investigated experimentally. Unless otherwise stated, the experiments were conducted at a Mach number of 0.20 .

\section{Computational Validation}

The experimental data shown in Figure 10 verify that the NASA cruise airfoil generates more lift over most of the angle of attack range than the reference airfoil, as predicted by INS2D. The additional camber (as compared to the reference airfoil) increased the loading over the entire airfoil (Figure 11). INS2D's predictions for the lift are in excellent agreement with experimental data for angles of attack up to $10^{\circ}$. However, INS2D did not accurately predict the stall angle (flow breakdown) of either airfoil. In addition, INS2D incorrectly predicted that the NASA airfoil would generate significantly higher maximum lift than the reference airfoil. INS2D did not accurately predict the onset and severity of 
trailing-edge separation, as indicated by the sharp decrease in trailing-edge pressures shown in Figure 12. Furthermore, INS2D did not correctly predict the qualitative differences in the stall types for the two airfoils. INS2D predicted both airfoils to exhibit a trailing-edge type stall, as indicated by the gradual rounding over of the lift curves at maximum lift in Figure 10. The NASA airfoil experimental results did exhibit this trailing-edge type stall. However, the reference airfoil experimental results exhibited more of a leading-edge type stall (normally characterized by the abrupt loss in lift after stall).

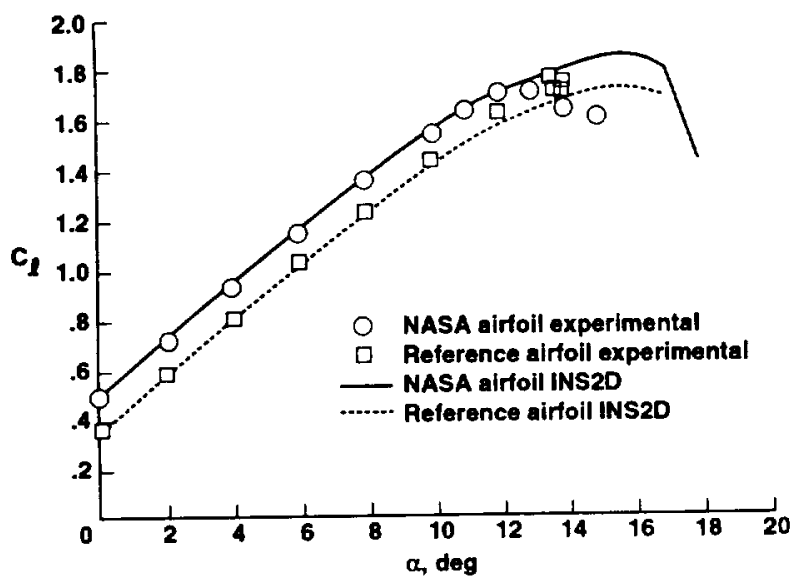

Figure 10. A comparison between experimental and INS2D predicted performance of the NASA and reference cruise airfoils $\left(M_{\infty}\right.$ $\left.=0.20, \operatorname{Re}_{\mathrm{C}}=9 \times 10^{6}\right)$.

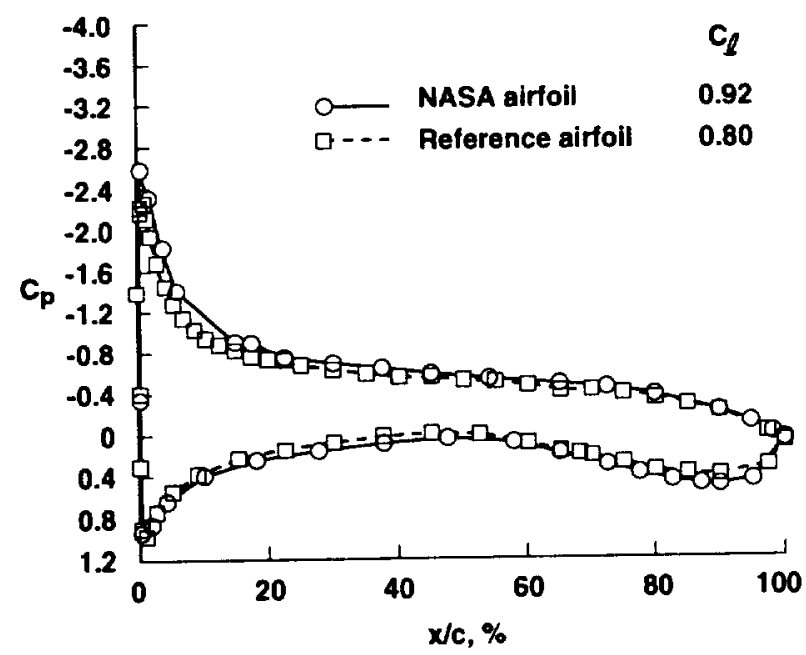

Figure 11. A comparison of experimental pressure distributions for the NASA and reference cruise aiffoils $\left(\mathrm{M}_{\infty}=0.20, \mathrm{Re}_{\mathrm{c}}=9 \times 10^{6}\right.$, $\alpha=4^{\circ}$ ).

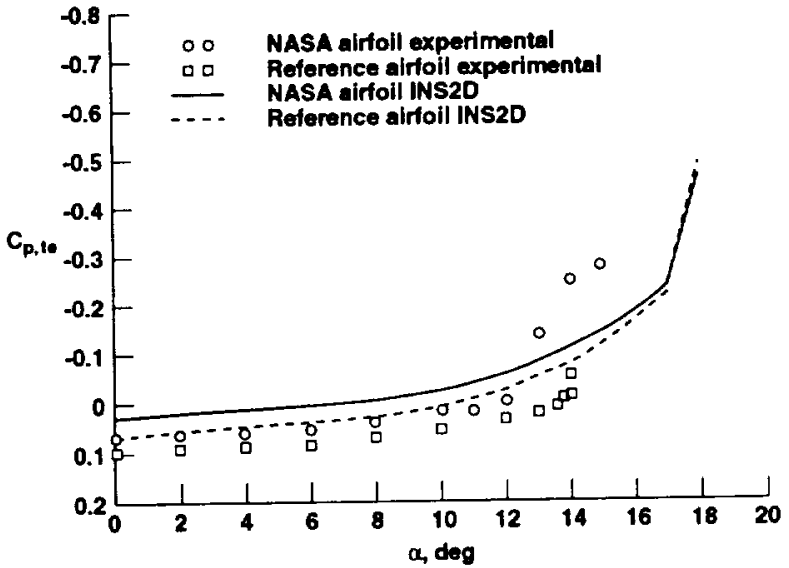

Figure 12. A comparison between experimental and INS2D predicted trailing-edge pressures of the NASA and reference cruise airfoils $\left(M_{\infty}=0.20, \operatorname{Re}_{c}=9 \times 10^{6}\right)$.

The initial multi-element testing was performed with the slat overhang and gap set at $-2.5 \%$ and $2.95 \%$, respectively, and the flap overhang and gap set at $0 \%$ and $1.27 \%$, respectively. These values were the design rigging for the three-element airfoil and are close to the optimum rigging of the reference airfoil ${ }^{4}$. As will be shown later, this rigging was very close to the best rigging (determined experimentally). A comparison of the experimental and INS2D predicted performance for the threeelement airfoils is shown in Figure 13. As can be seen, the code did not accurately predict the performance of the two airfoils near maximum lift. INS2D does capture the differences in performance between the NASA and reference airfoils over a large portion of the angle-of-attack range below stall. Specifically, at an approach condition $\left(-8^{\circ}\right.$ angle of attack), INS2D's prediction for the increased lift of the NASA airfoil relative to the reference airfoil is in good agreement with the experimentally observed increase. The difference between the experimental and INS2D results near the maximum lift may be, at least partially, attributed to the lack of boundarylayer transition simulation (computations were fully turbulent) and the possible compressibility effects near stall. 


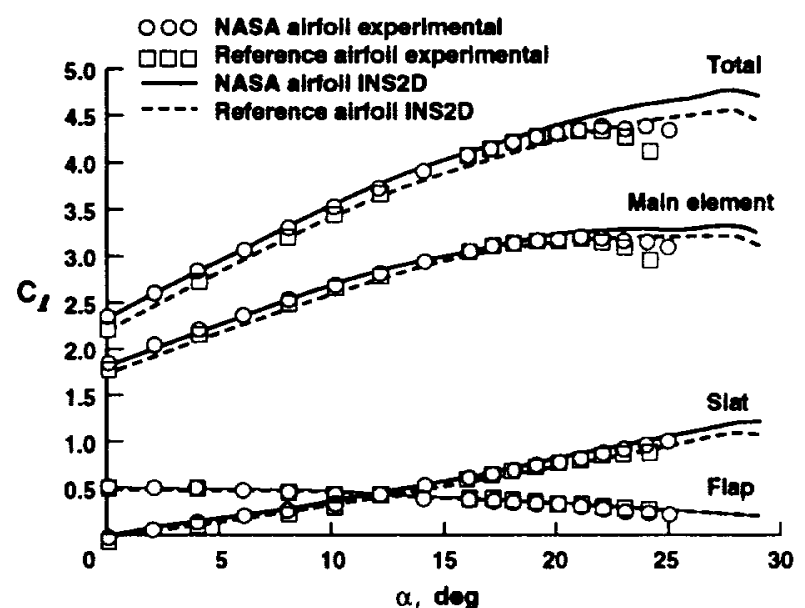

Figure 13. A comparison between experimental and INS2D predicted performance of the NASA and reference high-lift airfoils $\left(M_{\infty}=0.20, \operatorname{Re}_{c}=9 \times 10^{6}\right)$.

\section{Leading-Edge Slat-Rigging Effects}

For this portion of the study, the flap was set at $30^{\circ}$ deflection with an overhang of $0 \%$ and a gap of $1.27 \%$. The flap position was fixed while the slat overhang and gap were varied. The effect of Reynolds number on leading-edge slat-rigging effects is shown in Figure 14. At the $4.2 \times 10^{6}$ Reynolds number, there are two possible optimum positions. The $4.2 \times 10^{6}$ Reynolds number is a typical chord Reynolds number for many full-span, threedimensional, low-speed wind-tunnel tests. The maximum-lift value realized for the airfoil in this test is highest at the lower Reynolds number. Thus rigging the slat based on low Reynolds number testing would lead the designer to chose a rigging that is clearly not optimum at the higher Reynolds numbers. The best slat rigging for this study was at a gap of $2.44 \%$ and an overhang of $-1.5 \%$.

In examining the results shown in Figure 14, it can be seen for the $-2.5 \%$ overhang case the effect of gap on maximum lift is clearly Reynolds number dependent. When the slat gap is increased from $2.94 \%$ to $3.27 \%$, there was a sharp decrease in the maximum-lift coefficient for Reynolds numbers of 4.2 and $9 \times 10^{6}$, respectively. However, at the highest Reynolds number, the maximum-lift level remains essentially unchanged for the three gaps tested. The effects of slat gap on the lift curves for 9 and $16 \times 10^{6}$ Reynolds numbers are shown in Figures 15 and 16, respectively, for the $-2.5 \%$ overhang. At $9 \times 10^{6}$ Reynolds number, increasing the gap reduces the loading on the main element by reducing the WUSS suction peak, as shown in Figure 17 for an angle of attack just below stall. However, at $16 \times 10^{6}$ Reynolds number, the main-element (and total) loading does not change appreciably, as illustrated in Figures 16 and 18 . This could be caused by the boundarylayer/wakes becoming thinner as Reynolds number increased, decreasing the gap sensitivity of the main element (for the gaps tested at this overhang).
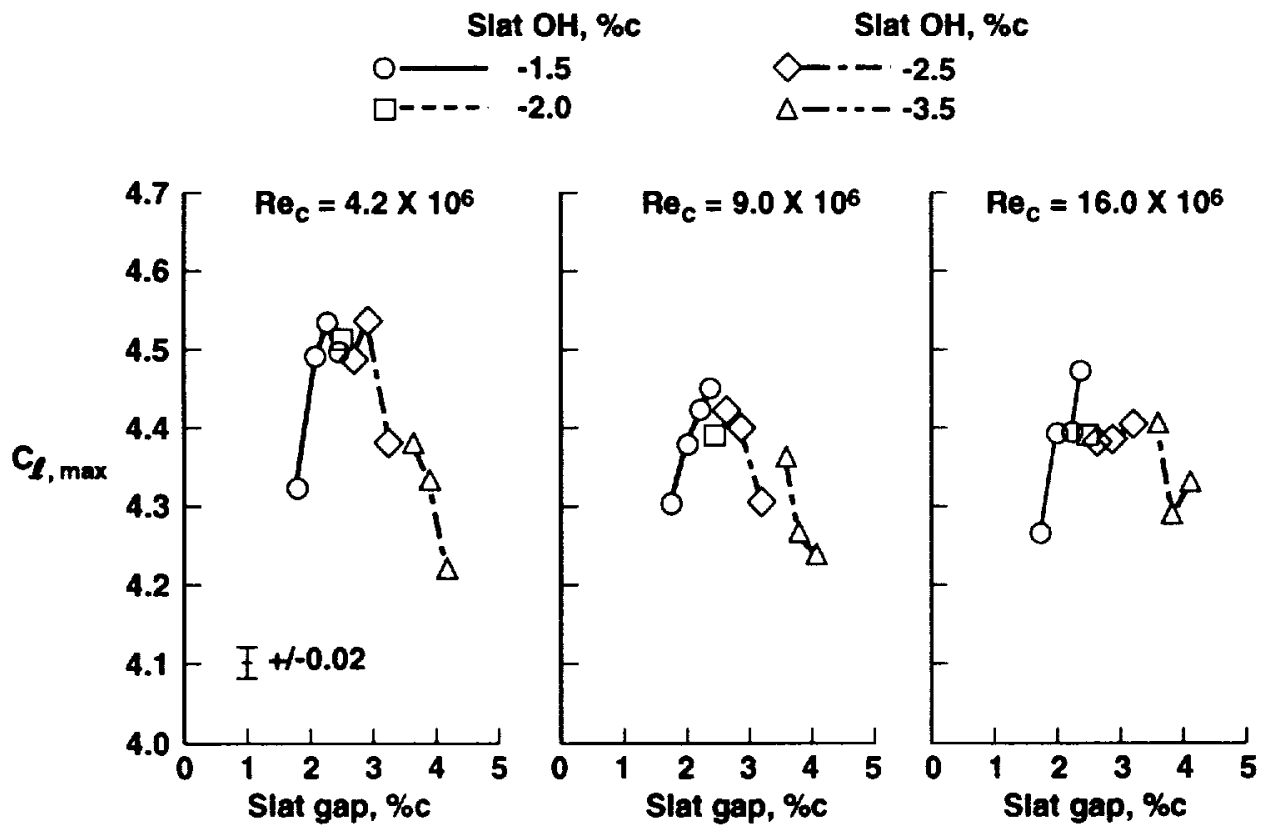

Figure 14. Effect of Reynolds number on leading-edge slat optimization $\left(\mathrm{M}_{\infty}=0.20\right)$. 


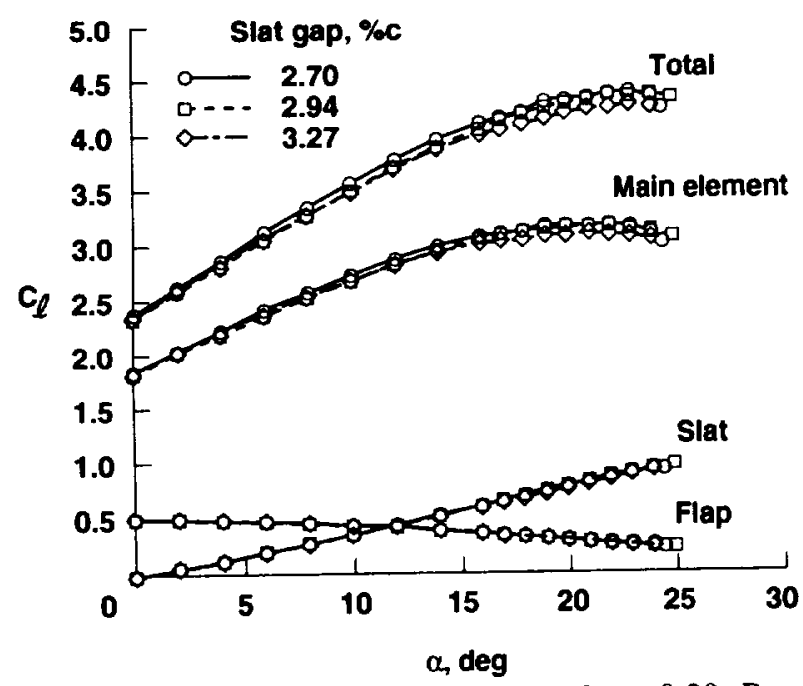

Figure 15. Effect of slat gap on lift $\left(M_{\infty}=0.20, R_{c}\right.$ $=9 \times 10^{6}$, Slat $\mathrm{OH}=-2.5 \%$ ).

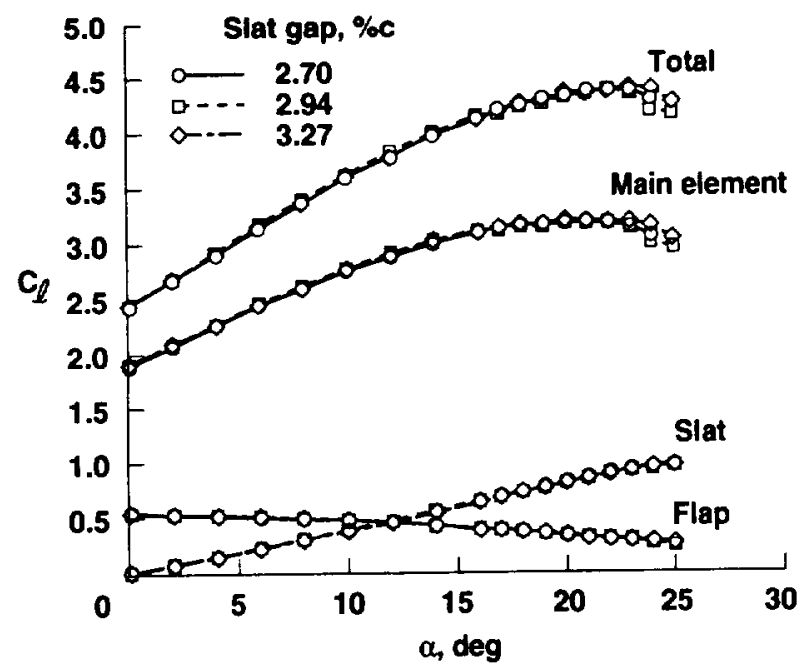

Figure 16. Effect of slat gap on lift $\left(\mathrm{M}_{\infty}=0.20, \mathrm{Re}_{\mathrm{C}}\right.$ $=16 \times 10^{6}$, Slat $\mathrm{OH}=-2.5 \%$ ).

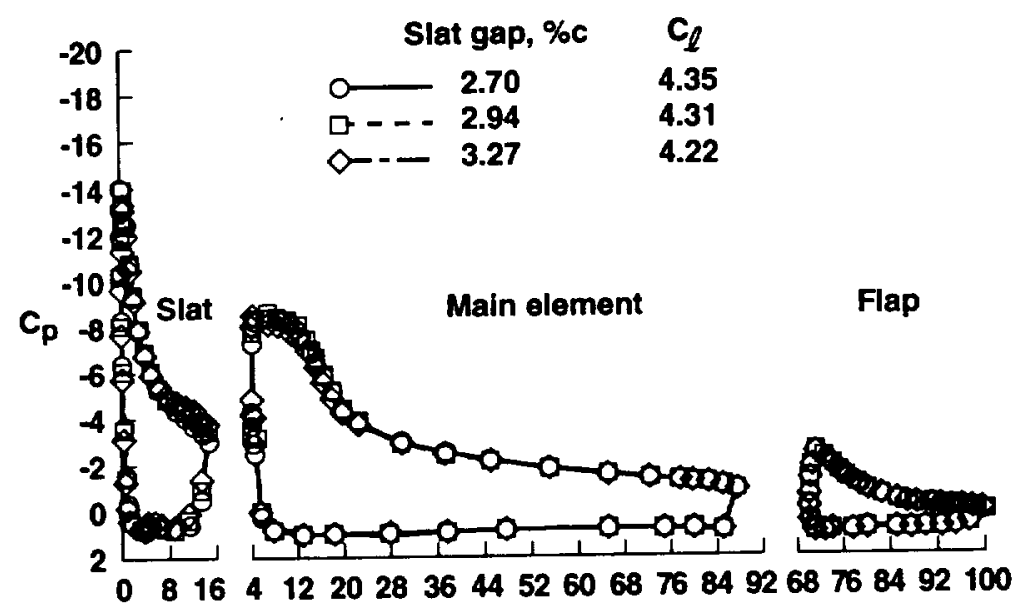

$$
\mathrm{x} / \mathrm{c}, \%
$$

Figure 17. Effect of slat gap on surface pressures $\left(\mathrm{M}_{\infty}=0.20, \mathrm{Re}_{\mathrm{c}}=9 \times 10^{6}\right.$, Slat $\left.\mathrm{OH}=-2.5 \%, \alpha=20^{\circ}\right)$.

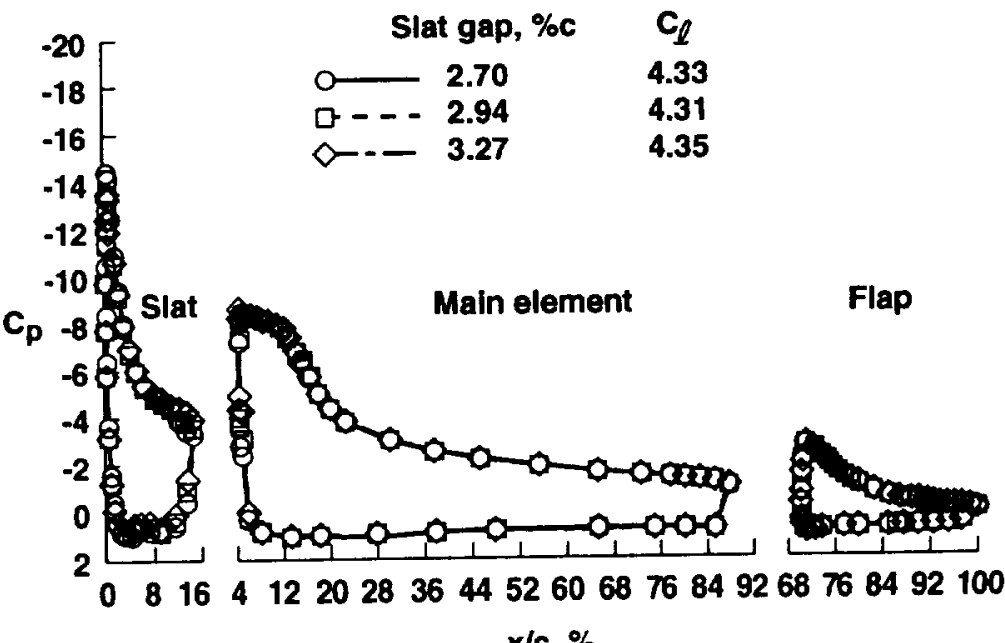

Figure 18. Effect of slat gap on surface pressures $\left(\mathrm{M}_{\infty}=0.20, \mathrm{Re}_{\mathrm{c}}=16 \times 10^{6}\right.$, Slat $\left.\mathrm{OH}=-2.5 \%, \alpha=20^{\circ}\right)$. 
From Figures 15 and 16, it can be seen that changing the slat gap clearly influences the mainelement loading, and subsequently the slat loading. For the increase in slat gap from $2.94 \%$ to $3.27 \%$ shown in Figure 15, there is a noticeable decrease in the main-element (and slat) loading at the higher angles of attack due to the reduced suction peak. From these results it can be inferred that the change in performance is due primarily to changes in the main-element loading. The reduction in WUSS suction peak led to a corresponding reduction in the slat lift in the form of a reduced aft loading. Thus a change in slat gap (for a constant overhang) acts on the main element, and the main-element loading influences slat and flap loading. In comparison, the slat deflection study of Reference 2 showed a change in slat deflection acts first on the slat itself, and the main-element and flap loading are subsequently impacted (the main-element loading does decrease as the slat loading increased).

\section{Trailing-Edge Flap-Rigging Effects}

For this portion of the study, the slat position was fixed at the optimum location as determined from the previous study, i.e. a gap of $2.44 \%$ and an overhang of $1.5 \%$. The flap deflection was fixed at $30^{\circ}$, and its overhang and gap were varied. The effect of Reynolds number on trailing-edge flaprigging effects is shown in Figure 19. The effect of Fowler motion (extending the effective chord of the high-lift system) on maximum lift is prevalent in Figure 19. As the overhang becomes more negative (no overlap), the maximum-lift values steadily increase. However, flow separation occurred on the flap for most of the cases that had a negative overhang. Thus the optimum point was a compromise of maximum lift and minimum flow separation (drag) at an approach-type condition. The best gap and overhang tested was a gap of $1.47 \%$ and an overhang of $-0.25 \%$. These values are very close to the design values of gap and overhang $(1.27 \%$ and $0 \%$, respectively).

The effect of overhang on flap performance is shown in Figure 20. It can be observed that the lift is significantly reduced and the drag drastically increased when the overhang is increased to $-1.0 \%$. This is due to the massive separation on the flap, as shown in the pressure distributions of Figure 21. This massive separation on the flap can have a global effect on the flow over the upper surfaces of the entire high-lift system. The separation reduced the flap loading as well as the upwash (from the flap) on the main element and slat, thereby reducing their respective loading (Figure 21). As the angle of attack is increased, the flap effective angle of attack is reduced due to increased wake spreading from the forward elements. At $\alpha=20^{\circ}$, the flap angle of attack is reduced sufficiently to reattach the flow, increasing the loading on the flap and consequently the main element (due to increased upwash from the flap), and thus the total loading (Figure 22). This demonstrates the importance of keeping the flow attached on the flap, since the lift generated at an approach condition $\left(8^{\circ}\right)$ is significantly reduced (and the drag is significantly increased) for the separated case even though the maximum lift values are almost identical.

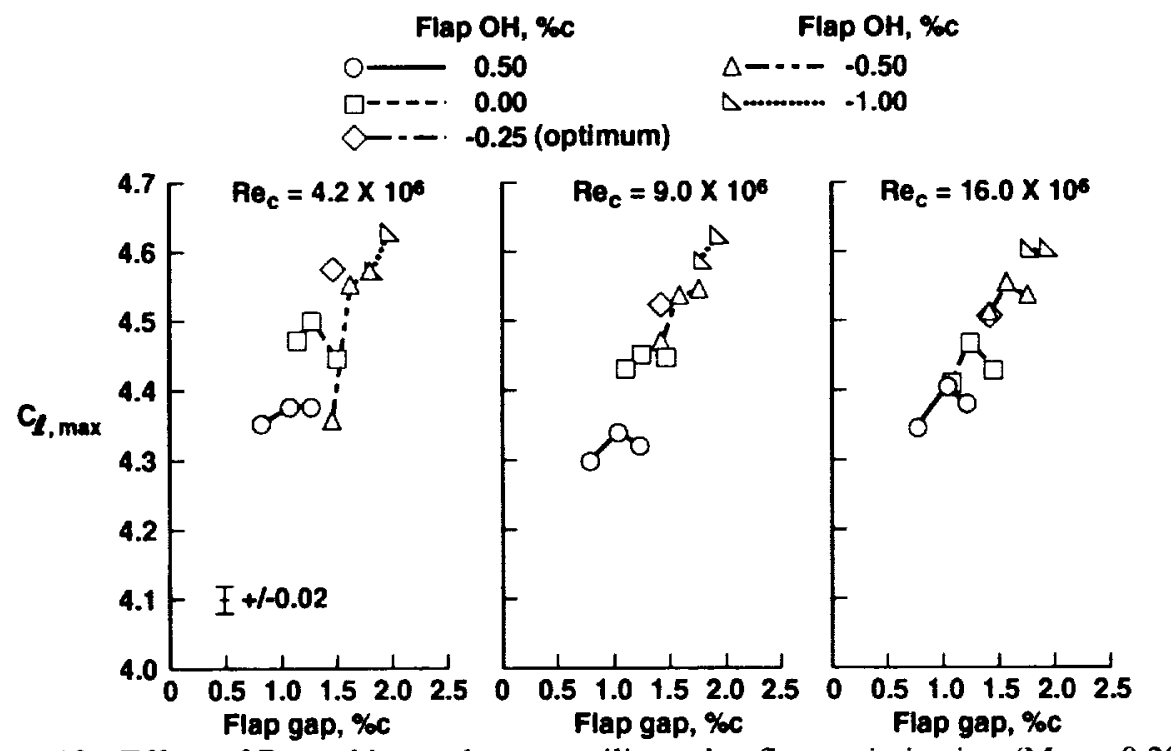

Figure 19. Effect of Reynolds number on trailing-edge flap optimization $\left(\mathrm{M}_{\infty}=0.20\right)$. 

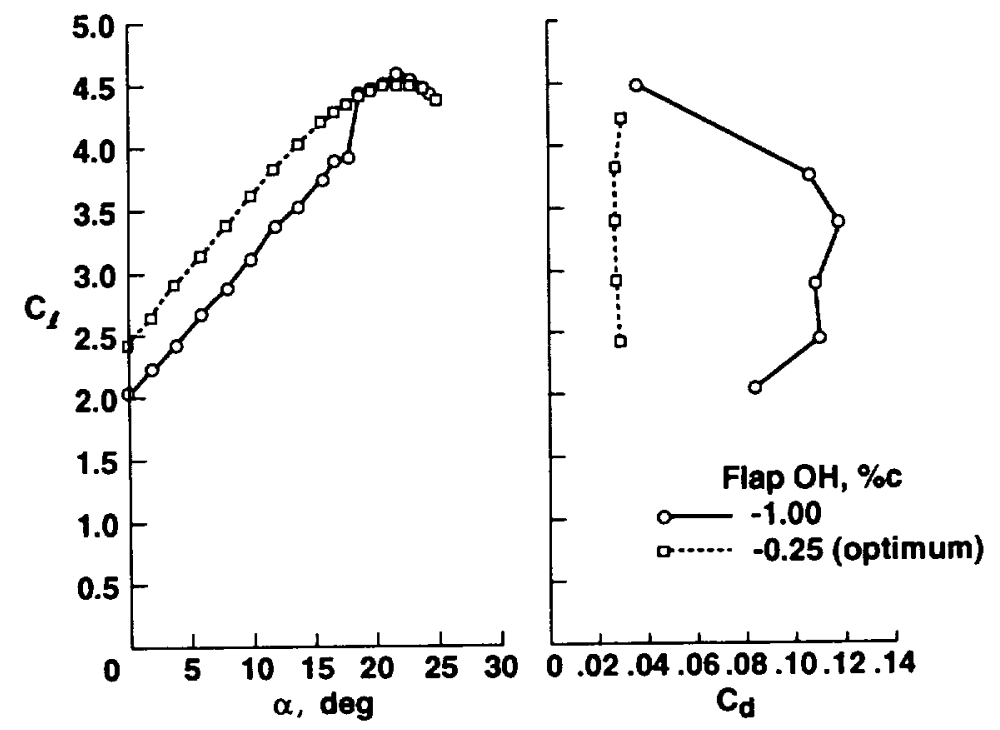

Figure 20. Effect of flap overhang on lift and drag $\left(M_{\infty}=0.20, \operatorname{Re}_{c}=16 \times 10^{6}\right)$.

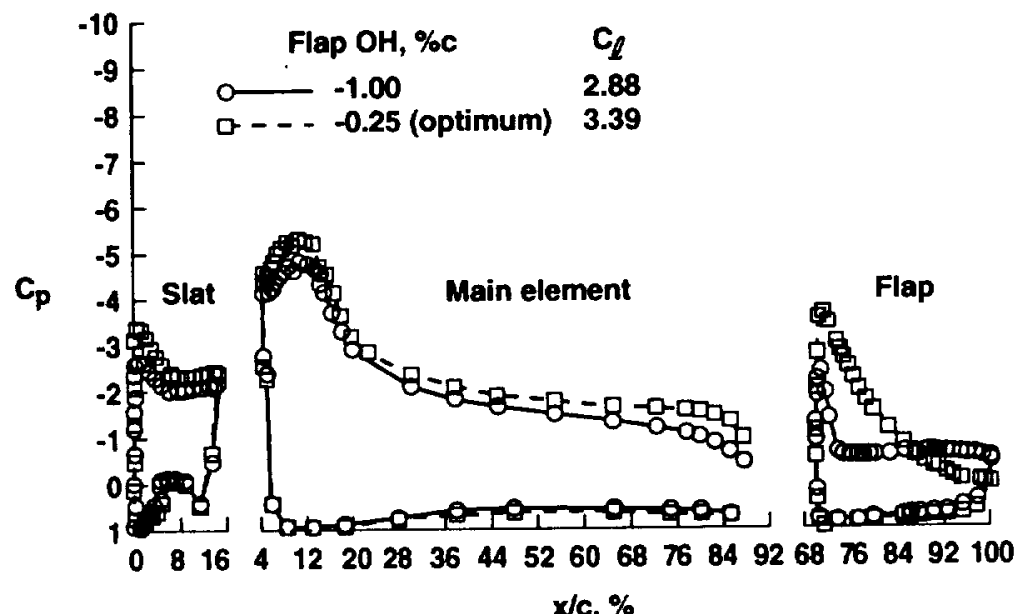

Figure 21. Effect of flap overhang on surface pressures $\left(M_{\infty}=0.20, \operatorname{Re}_{c}=16 \times 10^{6}, \alpha=8^{\circ}\right)$.

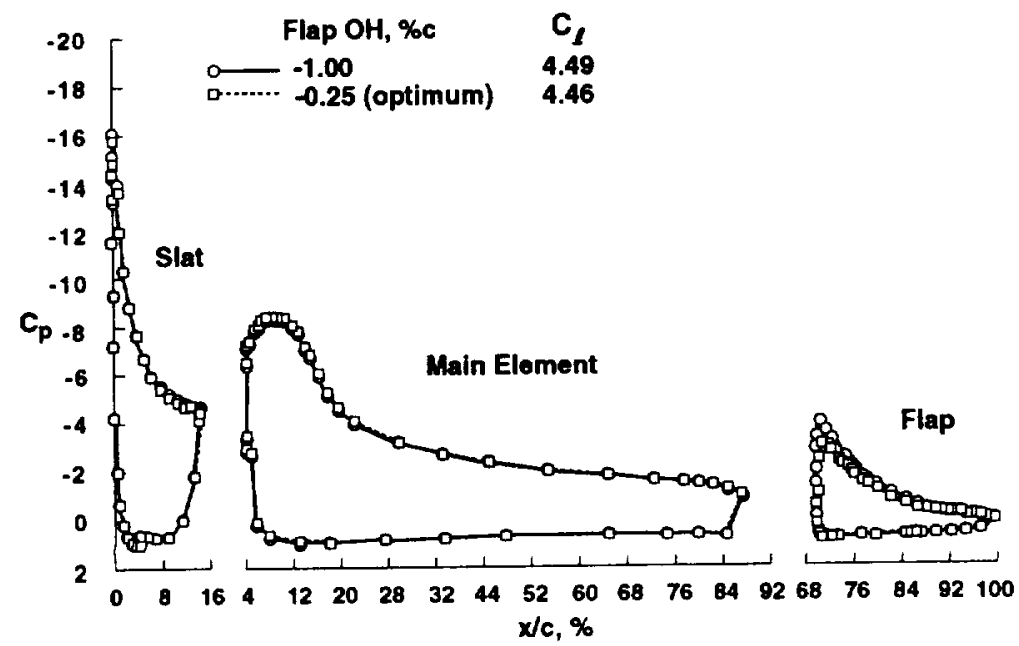

Figure 22. Effect of flap overhang on surface pressures $\left(M_{\infty}=0.20, \operatorname{Re}_{C}=16 \times 10^{6}, \alpha=20^{\circ}\right)$. 


\section{Reynolds and Mach Number Effects}

The Reynolds and Mach number effects on the best configuration are shown in Figures 23 and 24, respectively. As can be seen in Figure 23, the lift is almost identical and well behaved for chord Reynolds numbers of 9 and $16 \times 10^{6}$. However, there is a slight difference between these lift curves and that of the $4.2 \times 10^{6}$ case at approach conditions. This difference is due to flow separation that occurred on the flap between $4^{\circ}$ and $14^{\circ}$ angle of attack at the lower (non-flight scale) Reynolds number. Similar to results reported in References 2, 3, and 4, the measured maximum-lift levels of Figure 24 exhibit a significant dependence on Mach number at a given chord Reynolds number of $9 \times 10^{6}$. The (expected) compressibility effect at 0.26 Mach number limited the slat suction peak (see Figure 25) and causes the stall to occur at a lower angle of attack as compared to the 0.15 and 0.20 Mach number results. The peak Mach number on the slat (at all freestream Mach numbers tested) significantly exceeded sonic values. The critical (sonic) $C_{p}$ for $M_{\infty}=0.26$ is about -9.4 . As can be seen in Figure 25, the maximum $C_{p}$ on the slat is much greater than this value.

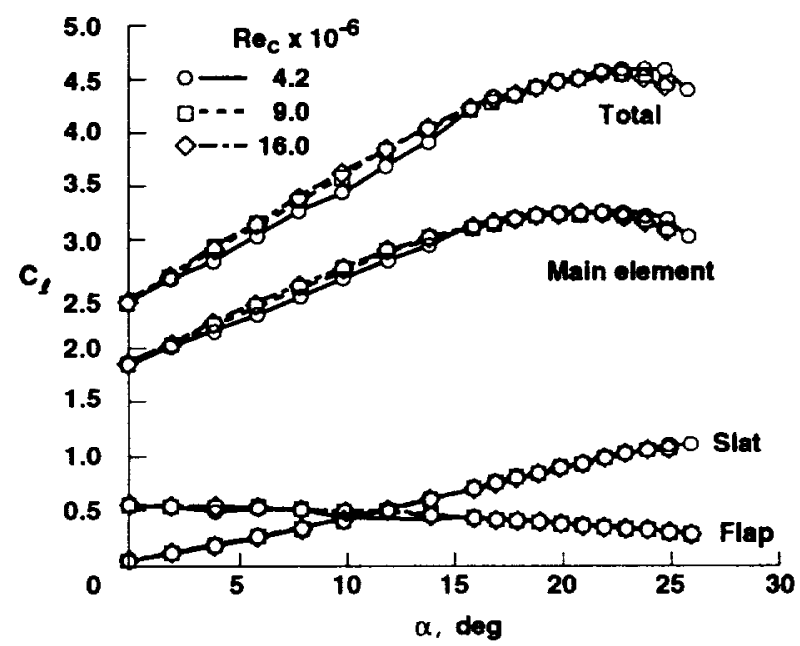

Figure 23. Effect of Reynolds number on lift curves of optimum configuration $\left(\mathrm{M}_{\infty}=0.20\right)$.

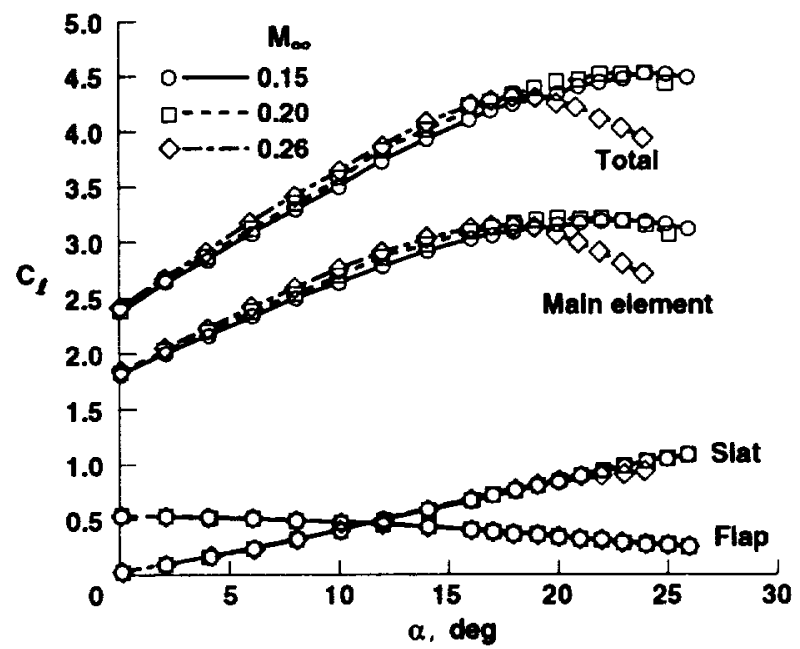

Figure 24. Effect of Mach number on lift curves of optimum configuration $\left(\operatorname{Re}_{\mathrm{C}}=9 \times 10^{6}\right)$.

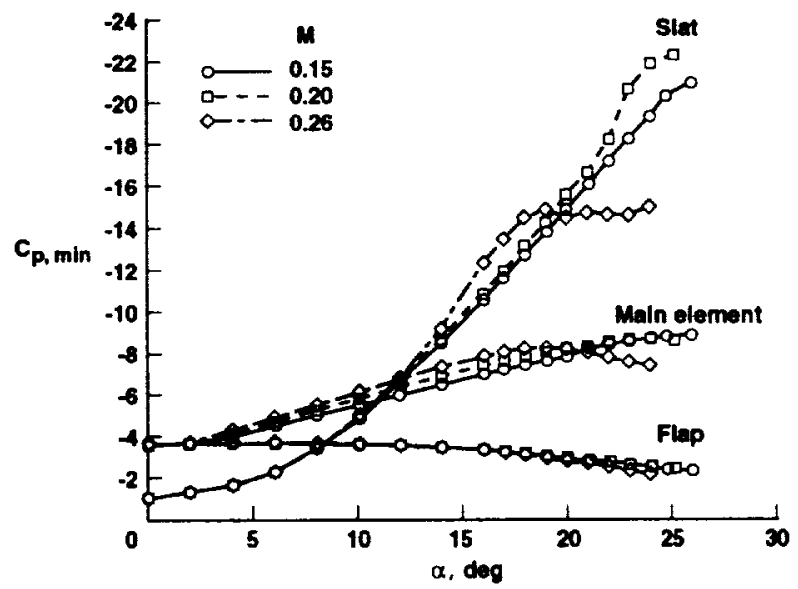

Figure 25. Effect of Mach number on suction-peak pressures of optimum configuration $\left(\operatorname{Re}_{\mathrm{c}}\right.$ $\left.=9 \times 10^{6}\right)$.

\section{Conclusions}

New high-lift airfoil components have been designed using INS2D for the NASA EET high-lift research airfoil. The new components have been tested in the NASA Langley LTPT and the effects of Reynolds number and Mach number on performance have been studied. Several salient conclusions can be drawn from this work.

- The structured-grid Navier-Stokes method INS2D accurately predicted the lift and performance difference of the NASA and the reference airfoils at approach conditions for the single-element (cruise) and three-element (high-lift) airfoils. 
However, INS2D using the one-equation Baldwin-Barth turbulence model did not accurately predict the experimentally observed maximum-lift values of either airfoil.

- Significant Reynolds number effects were observed on the leading- and trailing-edge rigging effects. The maximum-lift values decreased as Reynolds number increased for the leading-edge rigging studied. The sensitivity to gap was also very Reynolds number dependent for some of the slat (and flap) overhangs tested.

- Separation occurred on the single-segment flap for the negative-overhang cases tested in this study. This is especially important since a separated flap generates increased drag (and associated noise and vibration), and possibly less total lift than the "best" flap with attached now at an approach condition.

While the present work has increased the existing database of leading- and trailing-edge rigging effects, it is apparent that more detailed work is needed. Specifically, studying the slat wake and main element interaction in more detail is necessary to understand the possible implications for high-lift system improvement. Also, an improved understanding of the boundary-layer transition process on each of the elements as a function of Reynolds number is urgently needed in order to determine how to properly simulate full-scale conditions on 3D high-lift systems. And, finally, much work is needed to develop turbulence models that better represent multielement airfoil flows in order to increase the role/effectiveness of CFD in the design process.

\section{Acknowledgments}

The authors would like to thank Ms. Betty S. Walker and Ms. Betty F. Millard for their significant contributions to the data reduction of this investigation. Furthermore, special thanks are extended to all members of the LTPT for their contributions during the course of this investigation.

\section{References}

1. Fidders, S. P., Kirby, D. A., Woodward, D. S., and Peckham, D. H., "Investigation Into the Effects of Scale and Compressibility on Lift and Drag in the RAE 5m Pressurized Low-Speed Wind Tunnel," Aeronautical Journal, Paper No. 1302, March 1985.
2. Valarezo, W. O., Dominik, C. J., McGhee, R. J., Goodman, W. L., and Paschal, K. B., "MultiElement Airfoil Optimization at High Reynolds Numbers," AIAA Paper No. 91-3332, September 1991.

3. Valarezo, W. O., Dominik, C. J., and McGhee, R. J., "Reynolds and Mach Number Effects on Multielement Airfoils," Fifth Symposium on Numerical and Physical Aspects of Aerodynamic Flows, California State University, Long Beach, January 1992.

4. Valarezo, W. O., Dominik, C. J., and McGhee, R. J., "High Reynolds Number Configuration Development of a High-Lift Airfoil," AGARD CP-515, Paper No. 10,71st AGARD FDP Symposium on High-Lift System Aerodynamics, Banff, Alberta, October 1992.

5. Morgan, H. L., Jr., "Model Geometry Description and Pressure Distribution Data from Tests of EET High-Lift Research Model Equipped with Full-Span Slat and Part-Span Flaps," NASA TM-80048, February 1979.

6. Rogers, S. E., Wiltberger, N. L., and Kwak, D., "Efficient Simulation of Incompressible Viscous Flow Over Single and Multi-Element Airfoils," AIAA Paper 92-0405, January 1992.

7. McGhee, R. J., Beasley, W. D., and Foster, J. M., "Recent Modifications and Calibration of the Langley Low-Turbulence-Pressure-Tunnel," NASA TP-2328, July 1984.

8. Paschal, K., Goodman, W., McGhee, R., Walker, B., and Wilcox, P., "Evaluation of Tunnel Sidewall Boundary-Layer-Control Systems for HighLift Airfoil Testing," AIAA Paper No. 91-3243, September 1991.

9. Wlezien, R. W., Spencer, S. A., and Grubb, J. P., "Comparison of Flow Quality in Subsonic Pressure Tunnels," AIAA Paper No. 94-2503, June 1994.

10. Lin, J. C., Robinson, S. K., McGhee, R. J., and Valarezo, W. O., "Separation Control on High Reynolds Number Multi-element Airfoils," AIAA Paper 92-2636, June 1992. 
